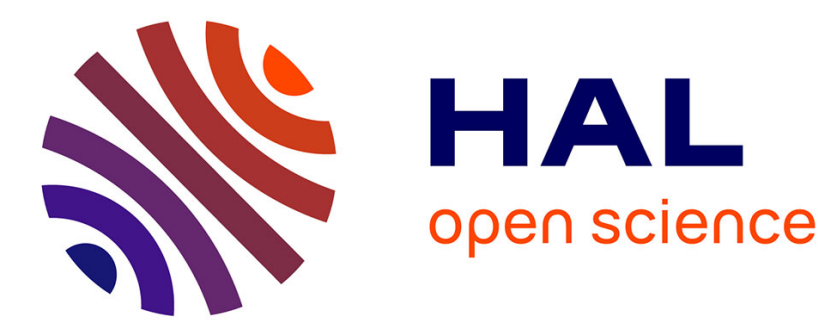

\title{
Tuning the rheology of polymer conducting inks for various deposition processes
}

\author{
Alizée Glasser, Eric Cloutet, Georges Hadziioannou, Hamid Kellay
}

\section{To cite this version:}

Alizée Glasser, Eric Cloutet, Georges Hadziioannou, Hamid Kellay. Tuning the rheology of polymer conducting inks for various deposition processes. Chemistry of Materials, 2019, 31 (17), pp.6936-6944. 10.1021/acs.chemmater.9b01387 . hal-02169663

\section{HAL Id: hal-02169663 \\ https://hal.science/hal-02169663}

Submitted on 2 Jul 2020

HAL is a multi-disciplinary open access archive for the deposit and dissemination of scientific research documents, whether they are published or not. The documents may come from teaching and research institutions in France or abroad, or from public or private research centers.
L'archive ouverte pluridisciplinaire $\mathbf{H A L}$, est destinée au dépôt et à la diffusion de documents scientifiques de niveau recherche, publiés ou non, émanant des établissements d'enseignement et de recherche français ou étrangers, des laboratoires publics ou privés. 


\title{
Tuning the rheology of polymer conducting inks for various deposition processes
}

\author{
Alizée Glasser, ${ }^{1,2}$ Éric Cloutet, ${ }^{1, *}$ Georges Hadziioannou, ${ }^{1, *}$ Hamid Kellay, ${ }^{2, *}$ \\ ${ }^{1}$ Laboratoire de Chimie des Polymères Organiques (LCPO), UMR 5629, CNRS - Université de Bordeaux -INP Bordeaux, \\ B8 Allée Geoffroy Saint Hilaire, F-33615 Pessac, Cedex, France \\ ${ }^{2}$ Laboratoire Ondes et Matière d'Aquitaine (LOMA), UMR 5798, CNRS - Université de Bordeaux, 351 cours de la \\ Libération, 33400 Talence, Cedex, France
}

\begin{abstract}
Organic semi-conducting polymers are attractive for their competitive price and their low processability requirements. Aqueous solutions of these polymers can be deposited with a variety of processes to make thin, flexible and transparent films. Such films can be used as transparent electrodes in organic light emitting diodes or organic photovoltaic cells. Poly(3,4-ethylene dioxythiophene):poly(styrenesulfonate) (PEDOT:PSS) is the only PEDOT:polyanion system which is commercially available. However, other counter-ions such as poly(4-styrene trifluoromethyl(bissulfonylimide)) (PSTFSI) have been shown to stabilize PEDOT in aqueous solvents and give comparable conductivity and transparency properties to the films. We show that the rheological properties of these two aqueous systems are especially different. For example PEDOT:PSTFSI inks can form a physical gel even at low concentrations, making it attractive for processing purposes while PEDOT:PSS shows only minor shear thinning behavior for concentrations as high as $1 \%$ wt. This difference in behavior is in part due to structural differences between the polyanions: PSTFSI favors hydrogen bonds while PSS does not. Here, we present a systematic study of the rheological properties and the film properties of PEDOT:PSTFSI inks for different concentrations and using various deposition processes such as doctor blade, screen-printing, inkjet, and soft blade deposition. We show that such inks can be adapted to each of these processes by simply tuning the concentration, making their formulation simple while keeping comparable optoelectronic properties as commercial inks.
\end{abstract}

\section{INTRODUCTION}

Transparent electrodes are used in optoelectronic devices such as organic light-emitting diodes (OLEDs) and organic photovoltaic cells (OPV). High transmittance and high conductivity ${ }^{1}$ are required for transparent electrodes. Different materials are used to elaborate such transparent elctrodes. The most widely used is indium-tin oxide (ITO) due to its low sheet resistance, high transparency and high stability. ${ }^{2}$ However, the raw material is expensive and the processing conditions require high temperatures (which is not compatible with top electrodes for organic devices) and high vacuum. Further, ITO based electrodes are not flexible and need post treatment to tune their so called work function ${ }^{2,3}$ to make them compatible with the organic layers used in OLED and OPV. Various alternatives to ITO have been developed for flexible transparent electrodes: metal layers, nanomaterials and conductive polymers. To increase transparency, metals have to be deposited in ultrathin layers, which leads to higher sheet resistance without necessarily improving the transmittance. Metals can also be deposited in grid patterns which improves the resistance and the transmittance. Metal nanowires, carbon nanotubes, or graphene have also been proposed as alternatives. However, in all these cases, the process to deposit the pattern (grids) or synthesize the nanomaterials is complicated and/or energy consuming. Also the patterns may have other defects such as electrical voids. ${ }^{2,4}$

To build organic flexible devices, transparent conductive polymers are a good alternative to ITO. One advantage of polymeric materials is that they can be easily deposited by printing processes from solution. The most commonly used and most widely studied polymer ink in terms of formulation to increase conductivity and transparency is poly(3,4ethylene dioxythiophene):poly(styrenesulfonate)

(PEDOT:PSS). This compound has interesting properties: sheet resistance $\mathrm{Rs}$ in the range $50<\mathrm{Rs}<1000 \Omega / \square$ and transmittance $\mathrm{T}$ in the range $75<\mathrm{T}<90 \%{ }^{2}$. To produce thin films using this ink, different deposition processes are used: flexography ${ }^{5}$, screen-printing ${ }^{6}$, rotogravure ${ }^{7,8}$, inkjet $^{9,10}$, offset, slot-dye ${ }^{11}$, doctor blade ${ }^{12}$, $3 \mathrm{D}$ printing ${ }^{13}$ etc. Each process has its benefits and 
drawbacks and needs an ink with specific rheological properties. ${ }^{14}$ For example, a fluid ink with low viscosity (5-40mPa.s) is needed for inkjet printing ${ }^{15,16}$, while a viscous shear thinning ink with elastic behavior or possessing a yield stress is required for doctor-blading and screen-printing ${ }^{17}$. A key property to allow a good processability of the ink is therefore its viscosity and its rheological behavior. The rheological properties of an ink may depend on different parameters such as the deformation $\gamma$, the processing time $\mathrm{t}$ (thixotropic behavior), the processing shear rate $\dot{\gamma}=\frac{d \gamma}{d t}$, the temperature $\mathrm{T}$, etc. Inks may also have a yield stress $\tau_{0}$, that is the minimum shear stress $\tau$ above which the ink can flow.

To obtain the rheological properties of a solution, rheometers are usually used. To measure the solution viscosity, a shear rate $\dot{\gamma}$ is applied to the ink contained in different geometry cells and the corresponding shear stress $\tau$ is measured. The viscosity is calculated with the relation $\eta=\frac{\tau}{\dot{\gamma}}$. Newtonian fluids, for example, follow the relation $\tau=\eta \dot{\gamma}$ where the viscosity $\eta$ is constant. For so called Bingham fluids ${ }^{18}$, a yield stress $\tau_{0}$ is present and the stress is written as $\tau=\tau_{0}+k \dot{\gamma}$. Power-law fluids follow the Ostwald - de Waele relationship $^{19} \quad \tau=k \dot{\gamma}^{n}=\eta(\dot{\gamma}) \dot{\gamma}$ which leads to $\eta(\dot{\gamma})=k \dot{\gamma}^{n-1}$. For $\mathrm{n}<1$ the solution is shear thinning. For $n>1$, on the other hand, the fluid is shear thickening which is a behavior to avoid for printing processes. The Herschel-Bulkley model ${ }^{20}$ covers a large spectrum of behaviors using the yield stress $\tau_{0}$, the flow consistency index $\mathrm{k}$, and the flow behavior index $\mathrm{n}$ : the stress is given by $\tau=\tau_{0}+$ $k \dot{\gamma}^{n}$. Inks may also show elastic behavior. The elasticity of the ink is an important property to take into account. It can be determined using dynamic oscillation stress sweep. The complex shear modulus $G^{*}=G^{\prime}+i G^{\prime \prime}$ is measured and can be decomposed into two parts: the storage modulus $G^{\prime}$ represents the elastic behavior of the ink, and the loss modulus $G^{\prime \prime}$ gives the viscous contribution. Both are constant in the linear viscoelastic range. Hook's law models ideal elastic fluids: $G^{*}=\frac{\tau(t)}{\gamma(t)}=c s t$. In the case of ideal elastic fluid, $G^{\prime \prime}=0$; for an ideal viscous fluid, $G^{\prime}=0$. In the general case of a so called viscoelastic fluid: if $G^{\prime \prime}>G^{\prime}$ the fluid is a viscoelastic liquid, and if $G^{\prime}>G^{\prime \prime}$ the fluid is a viscoelastic gel (or soft solid). ${ }^{21}$
Herein we will focus on the formulation and characterization of a conductive polymer similar to PEDOT:PSS. Indeed, to stabilize PEDOT in water, other counter-ions can be used such as the polyanion poly(4-styrene trifluoromethyl(bissulfonylimide)) (PSTFSI) $^{22}$. As we will show below, this ink can be formulated using standard additives as for PEDOT:PSS for wettability and conductivity properties but presents a serious advantage: the rheology of the ink can be tuned over a wide range of behaviors by simply changing the concentration of the polymer. Small changes of this concentration allows going from very fluid inks to gel-like solutions. This versatility makes for a simple formulation of PEDOT:PSTFSI inks for a wide variety of deposition processes. The impact on the outcome of different printing processes will be discussed. Different types of deposition processes (doctor blade, soft blade, inkjet, and screen-printing) will be used to illustrate the resulting film properties in terms of homogeneity, conductivity, and transparency.

\section{RESULTS AND DISCUSSION}

The aim of this study is to formulate the PEDOT:PSTFSI inks for different deposition processes. Two crucial properties control the processability of the ink: the rheological properties controlled by the structure of the polymers as well as the concentration and the wetting properties which are partially controlled by the surface tension of the ink (to be compared with the free surface energy of the substrate).

\section{I) Ink Characterization: Rheology - from Newtonian to shear thinning and gel like solutions}

Figure 1 displays the shear stress $\tau$ versus shear rate $\dot{\gamma}$ and the viscosity obtained as $\eta=\frac{\tau}{\dot{\gamma}}$ for inks with different concentrations. For low concentrations, the solutions behave as Newtonian fluids as the stress varies linearly with the shear rate and the viscosity is roughly constant. As the concentration increases, the viscosity is no longer constant but varies with shear. This regime can be modeled using the power-law (PL) ${ }^{19}$ model $\tau=$ $k \dot{\gamma}^{n}$. For higher concentrations, two regimes appear. For high shear rates, the fluid continues to behave as a PL fluid. However, for lower shears the rheological behavior changes and the Herschel-Bulkley (HB) model ${ }^{20}$ becomes more relevant: $\tau=\tau_{0}+k \dot{\gamma}^{n}$. 


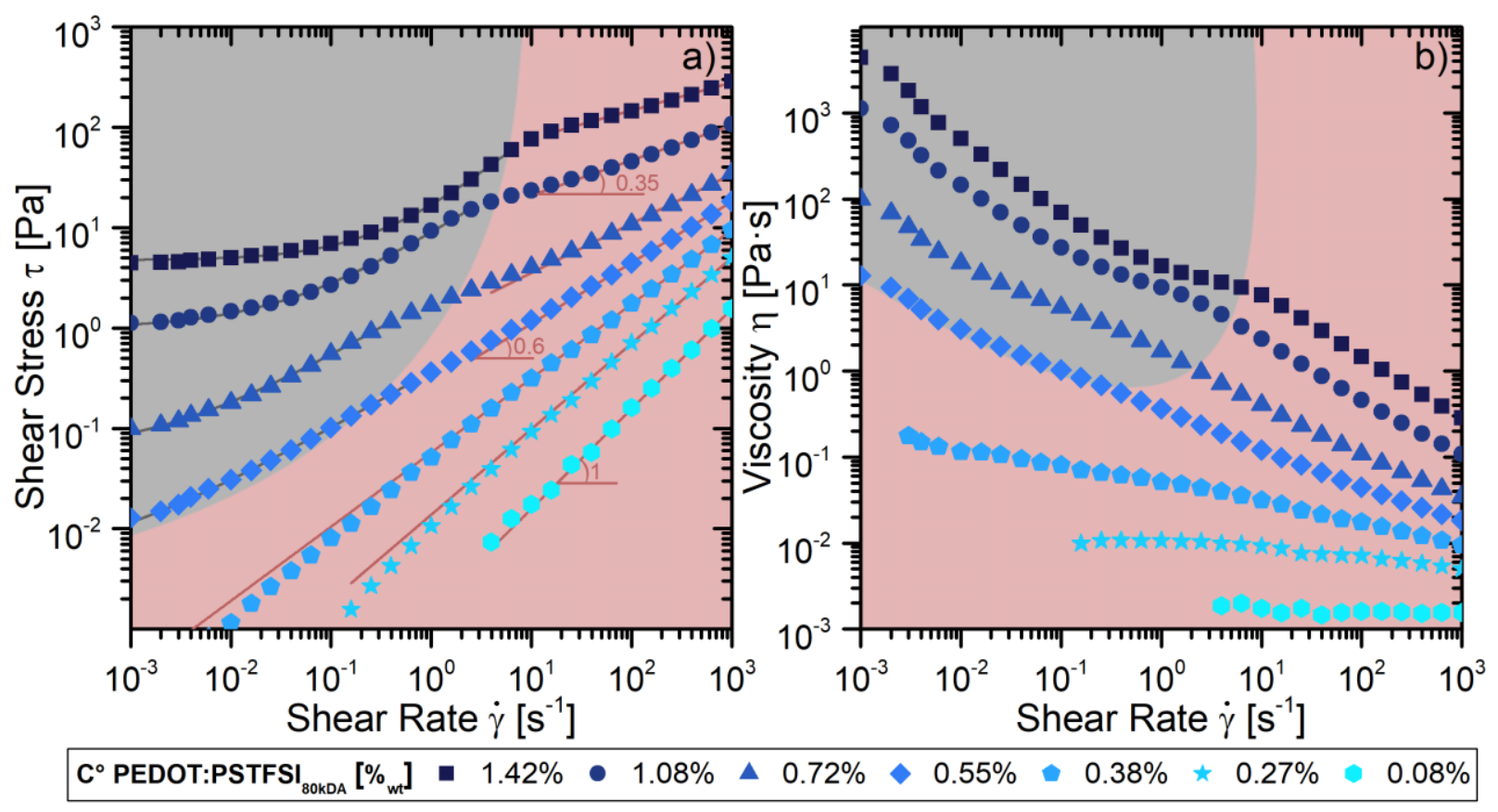

Figure 1. Rheological behavior of PEDOT:PSTFSI inks measured with a shear rheometer (cone plate geometry: $50 \mathrm{~mm}$ diameter and $1^{\circ}$ angle): a) shear stress versus shear rate and b) viscosity versus shear rate obtained by applying shear rate ramps at $18^{\circ} \mathrm{C}$. The lines are fits to the data using the power model (red) or the HB model (grey). The numbers are the values of the parameter $\mathrm{n}$.

Two regimes are therefore observed (grey and red regions in Figure 1). In the grey region, for low shear rate and high concentrations, the solutions behave according to the HB model. In the red region on the other hand, the yield stress is either too low to be measured or completely absent and the solutions behave as PL fluids. Figure 2 shows the yield stress $\tau_{0}$ [Figure 2.a] and the flow behavior index $n$ [Figure 2.b]. The yield stress becomes measurable after a threshold near $0.5 \%_{\mathrm{wt}}$ and increases with the concentration. The flow behavior index $\mathrm{n}$ starts near 1 for low concentrations, which behave as Newtonian fluids, and decreases with the increase of the concentration, indicating that the ink becomes more and more shear thinning. The value of $n$ extracted in the HB regime depends mildly on concentration and has a value near 0.6. For the high concentrations, the increase in shear rate at which the change in regime for a HB to a PL fluid occurs is not constant and increases with the concentration. We believe that this change in behavior comes from the fact that the PSTFSI polyanion creates hydrogen bonds near the nitrogen atom ${ }^{23}$ [Figure 3] and that the yield stress is the result of these hydrogen bonds. This is consistent with the increase in the yield stress with concentration. The increase in shear must break such bonds and therefore drastically reduce the yield stress and induce a change in the rheological behavior from an HB fluid to a PL fluid.

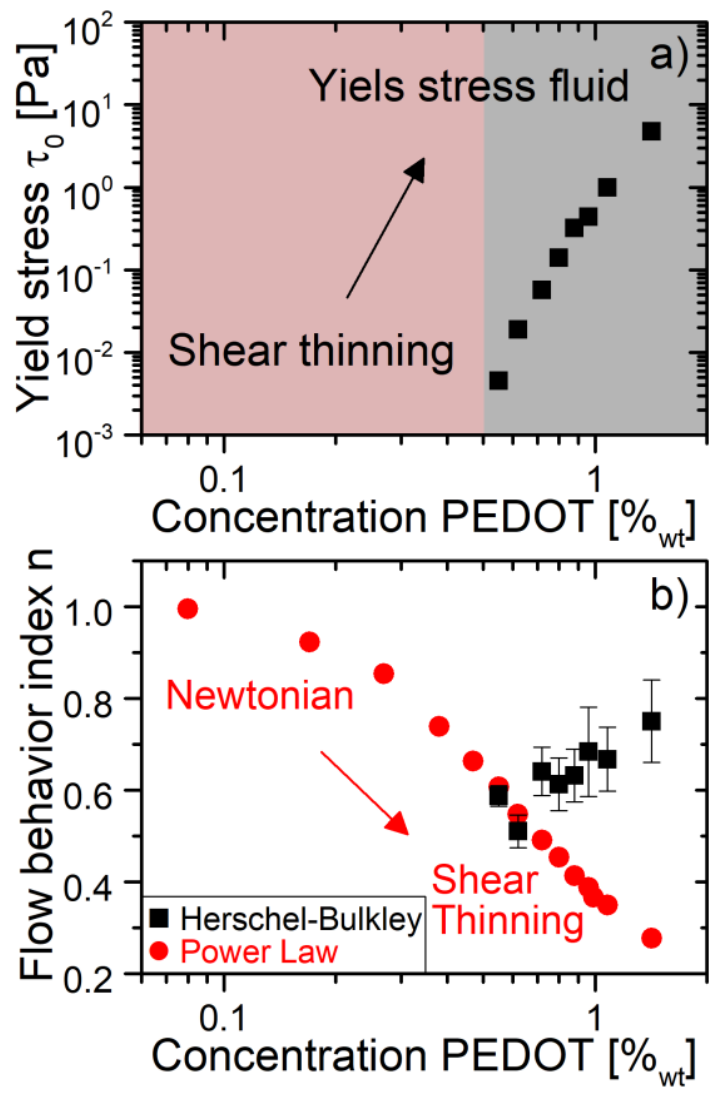

Figure 2. Herschel-Bulkley regime (grey region) and power-law regime (red region) parameters obtained from the shear stress curves of PEDOT:PSTFSI ${ }_{80 \mathrm{kDa}}$ inks [Figure 1]: a) yield stress $\tau_{0}$ and $b$ ) flow behavior index $n$. 
Besides concentration effects, both the viscosity and the yield stress can be varied by changing the molar mass of the polyanion. Experiments using different molar masses of the polyanion have shown that higher molar masses lead to higher viscosities as expected. Further, increasing the molar mass also increases the yield stress: for a polyanion of $250 \mathrm{kDA}$ molar mass instead of $80 \mathrm{kDA}$ as for the above results, the yield stress increases by almost an order of magnitude for identical concentrations [See Figures S.1 and S.2 in Supplementary Information].

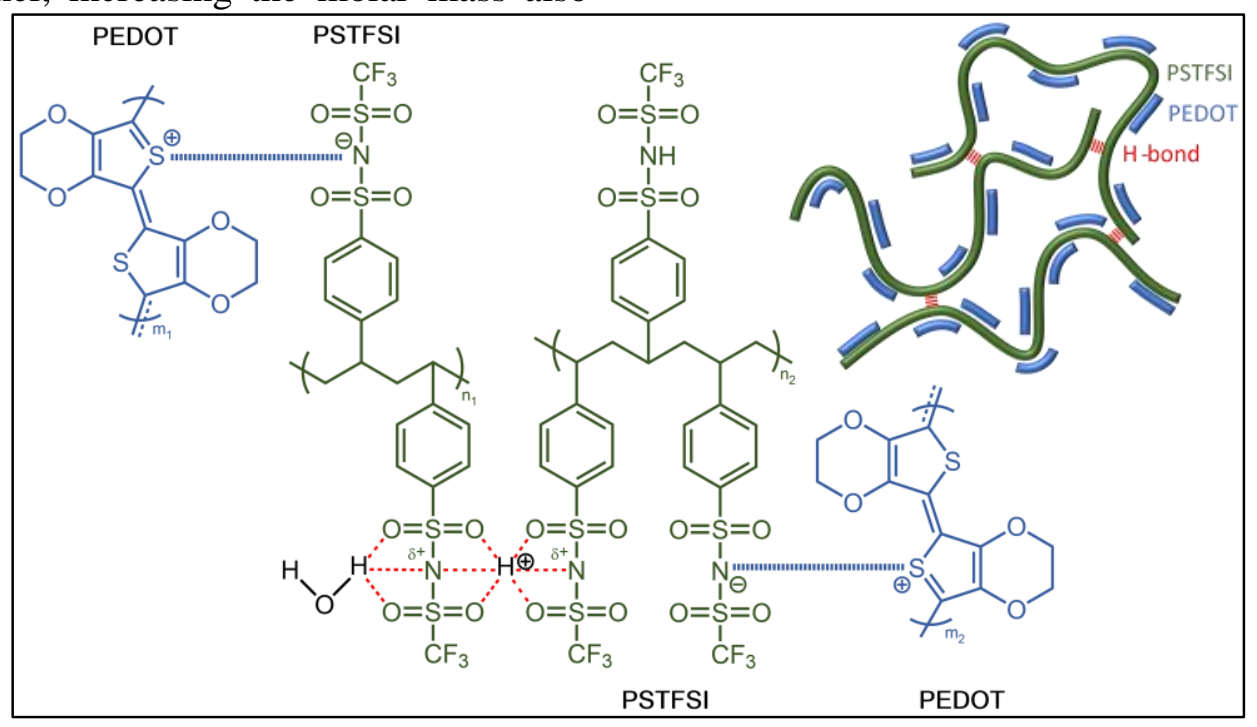

Figure 3. Structure and schematic representation of the complex PEDOT:PSTFSI (poly(3,4-ethylene dioxythiophene):poly(4-styrene trifluoromethyl (bissulfonylimide)) showing probable hydrogen bonds ${ }^{23}$ between polyanions.

To complete the above shear rheology measurements, we have performed dynamic oscillatory stress sweep measurements: a sinusoidal shear stress $\tau(t)=\tau_{A} \cdot \sin (\omega t)$ is imposed to the fluid and the corresponding deformation $\gamma(t)=\gamma_{A}$. $\sin (\omega t+\varphi)$ is measured (where $\gamma_{A}$ and $\tau_{A}$ are amplitudes, $\omega=2 \pi \cdot f$ is the imposed angular frequency which was fixed at $2 \pi$, and $\varphi$ is the phase shift between the deformation and the shear stress). The complex dynamic modulus $G^{*}$ is then expressed as: $G^{*}=\frac{\tau(t)}{\gamma(t)}=G^{\prime}+i G^{\prime \prime}$ where the storage modulus $G^{\prime}$ and loss modulus $G^{\prime \prime}$ represent the elastic and viscous parts of the viscoelastic behavior. When $G^{\prime}$ is higher than $G^{\prime \prime}$, the ink has a gel-like behavior. ${ }^{21}$ The higher $G^{\prime}$ and $G^{\prime \prime}$ are, the more elastic the gel is. The gel behaviors of PEDOT:PSTFSI ${ }_{80 \mathrm{kDA}}$ inks are displayed in Figure 4. For concentrations under $0.55 \%$, i.e. in the red region where we have previously shown that the ink has no yield stress, the ink is more viscous than elastic. By increasing the concentration, $G^{\prime}$ and $G^{\prime \prime}$ increase and $G^{\prime \prime}$ becomes smaller than $G^{\prime}$ : the ink becomes more elastic. The limit between the two regimes appears when $G^{\prime}=$ $G^{\prime \prime} \approx 50 \mathrm{mPa}$ and corresponds to a concentration of about $0.6 \%$. This is precisely where the H.B. behavior sets in and the solution becomes a yield stress fluid.
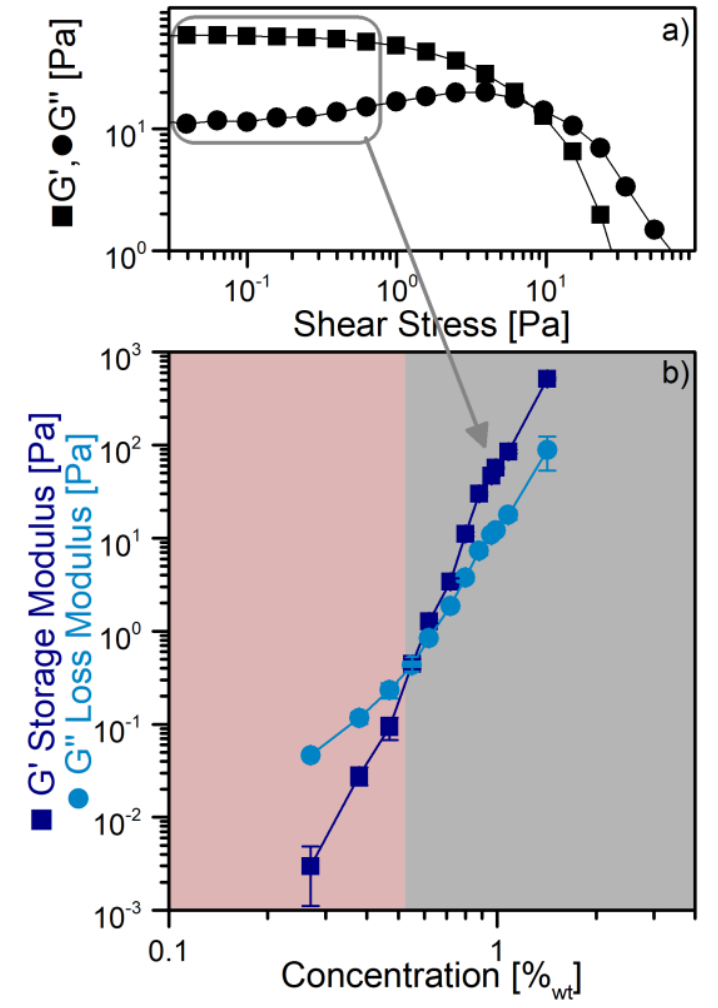

Figure 4. Rheological behavior of PEDOT:PSTFSI inks measured with a shear rheometer (cone plate geometry $50 \mathrm{~mm} / 1^{\circ}$ ): a) storage $G^{\prime}$ and loss $G^{\prime \prime}$ modulus obtained at a frequency of $1 \mathrm{~Hz}$ at $18^{\circ} \mathrm{C}$ for PEDOT:PSTFSI $80 \mathrm{kDa}$ at $0.99 \%$ wt in water versus stress. b) average value of $G^{\prime}$ and $G^{\prime \prime}$ in the linear viscoelastic range (i.e. in the plateau region of Figure 4.a) versus concentration. 
To summarize these rheology measurements, we have shown that the viscosity and elasticity of PEDOT:PSTFSI inks can be tuned by simply varying the concentration. This renders the formulation of such inks simple for different deposition processes going from inkjet printing which requires low viscosity Newtonian solutions to screen printing which requires elastic fluids. Changing the molar mass of the polyanion is also another means to tune the rheological behavior as it changes the viscosity, the yield stress, as well as the elasticity of the solutions.

Our solutions compare favorably with commercial PEDOT:PSS inks. For example, we have measured the properties of two commercial inks, Orgacon IJ 1000 (from Sigma Aldrich) and Clevios PH 1000 (from Heraeus) which can be used in inkjet printing. We have found slightly shear thinning behavior for the two inks with values of the viscosities in the range 0.3-1.4 Pa.s for 10-3 $\mathrm{s}^{-1}$ and 0.01-0.02 Pa.s for $10^{3} \mathrm{~s}^{-1}$. The storage and loss moduli for the two solutions were, respectively, $G^{\prime}=0.44 \pm$ $0.01 P a<G^{\prime \prime}=0.71 \pm 0.01 P a$ and $G^{\prime}=0.11 \pm$ $0.01 P a<G^{\prime \prime}=0.50 \pm 0.01 P a$. Another commercial ink used in screen-printing, Orgacon EL-P 5015 (from Sigma Aldrich) was characterized: a high shear thinning behavior was found with viscosities in the range $1.2 \cdot 10^{5} \mathrm{~Pa} . \mathrm{s}$ for $10^{-3} \mathrm{~s}^{-1}$ and 1.7 Pa.s for $10^{3} \mathrm{~s}^{-1}$, and a storage modulus $G^{\prime}=$ $237 \pm 6 \mathrm{~Pa}$ higher than the loss modulus $G^{\prime \prime}=$ $99 \pm 2 \mathrm{~Pa}$. To obtain this behavior for the commercial inks, PEDOT:PSS inks have to be concentrated to more than $5 \%$ wt, which is energy and time consuming. It must be emphasized that commercial PEDOT inks are already formulated complex fluids with a variety of different additives to tune their rheological properties. For the PEDOT:PSTFSI solutions studied here, only the concentration was changed to go from fluid like solutions to gel like ones.

II) Wettability: inks' surface tension versus substrate's surface energy

While rheology controls a number of properties relevant to the processing of inks, another important ingredient is the wettability of the substrate. The wettability is in part controlled by the surface tension of the solution: adapting surface tensions allows good wetting and a good adhesion of the ink onto the substrate. The inks used here have therefore been characterized by measuring their surface tensions. For dilute solutions of PEDOT:PSTFSI $(0.5 \%$ wt $)$ we obtain the same surface tension as water ( $\approx 72 \mathrm{mN} / \mathrm{m}$ ). By adding $0.04 \%$ wt surfactant (Zonyl FS-300 fluorosurfactant) or more to PEDOT:PSTFSI, the surface tension of the inks decreases drastically to almost $24 \mathrm{mN} / \mathrm{m}$. The concentration $0.04 \%_{\mathrm{wt}}$ of surfactant was chosen as it is above and near the critical micelle concentration of the surfactant in pure water (See Figure S.3 in Supplementary Information).

For higher concentrations of PEDOT:PSTFSI $(1 \%$ wt $)$ without surfactant, we obtain a surface tension of roughly $55 \mathrm{mN} / \mathrm{m}$. For these high concentrations, the PSTFSIK itself is surface active as solutions of this polyanion at a concentration of $1 \%$ have surface tensions near $60 \mathrm{mN} / \mathrm{m}$ (See Figure S.4 in Supplementary Information). The addition of surfactant $\left(0.04 \%_{\mathrm{wt}}\right.$ of Zonyl FS-300) to these high concentration solutions reduces the surface tension further to values near $24 \mathrm{mN} / \mathrm{m}$. The addition of surfactant may change the rheology of the solutions, however, measurements with and without surfactant show similar viscosities [See Figure S.5 in Supplementary Information].

For inkjet printing, surfactant must be added as it makes for a better wettability of the substrate. Indeed, and in the absence of surfactant, dewetting of drops on a glass substrate is observed leading to non-homogeneous films. Addition of surfactant in this case, improves the homogeneity of the films.

For doctor blade processing, the $1 \%_{\mathrm{wt}}$ PEDOT:PSTFSI allowed a good deposition on glass surfaces without need for surfactant. However, surfactant must be added for plastics like PET: the surface tension of the liquid needs to be lower than the surface energy of the substrate to have a complete wettability. The surface energy of glass was measured at $60 \pm 39 \mathrm{~mJ} / \mathrm{m}^{2}$ with an equal polar and dispersive part compared to the one of PET which was measured at $40 \pm 18 \mathrm{~mJ} / \mathrm{m}^{2}$ with a polar part ten times lower than the dispersive part. For the $1 \%_{\mathrm{wt}}$ PEDOT:PSTFSI, good wettability is obtained on glass (contact angle of $15^{\circ}$ ) while on PET the contact angle is four times higher and surfactant has to be added for good wettability.

For screen-printing, the screen has, with its roughness, a surface free energy of $20 \pm 1 \mathrm{mN} / \mathrm{m}$ almost completely dispersive $(18.5 \pm 1 \mathrm{mN})$. As we will see below, this partially explains the difficulty of the ink to flow through the mesh of the screen and the consequent inhomogeneity of the films obtained. 
The addition of surfactant in this case does not change the outcome considerably.

\section{III) Processing: Inkjet printing, Doctor blading, Screen-printing}

In general and in order to process inks using different techniques, different formulations have to be used. These formulations based on the use of different additives, adapt the rheological properties of the inks to the requirements of the printing technique. For example, inks for inkjet printing need to be of low viscosity and possess little elasticity.

On the other hand, inks adapted for doctor blading need to be shear thinning and, ideally, possess a yield stress. For screen-printing applications, gel like shear thinning solutions are preferred. In all these cases, the wetting properties of the inks on the substrates used have to be controlled as well.

The interest of the present system (PEDOT:PSTFSI), as we have shown in section I, is that one can go from a very fluid system to a gel like solution by simply changing the concentration. A change of the polyanion's molar mass is also another means to change the solution behavior. Thus, as far as the rheology is concerned, the formulation is simple.

These solutions can also be formulated to tune the wettability of the substrates through the addition of surfactant. For PEDOT based systems, it has also been shown that the addition of a high boiling point solvent (dimethyl sulfoxide (DMSO) or ethylene glycol (EG)) can enhance the conductivity of the films several fold. ${ }^{24}$ For this purpose, we have used $0.04 \%$ wt surfactant (Zonyl FS-300 fluorosurfactant) to enhance the wettability of the glass substrates used and $5 \%$ vol of a high boiling point solvent (DMSO, but test using EG have also been carried out with similar results) to enhance their conductivity. We have checked that the rheological and wettability properties are reasonably the same with and without $5 \%$ vol of DMSO or EG [See Figures S.5 and S.6 in Supplementary Information].

This section focuses on processing the (PEDOT:PSTFSI) inks using different techniques, inkjet printing, doctor blading, screen printing, and soft blading. In the following, we first give the properties of the films and in the next section we show the optoelectronic properties of the obtained films.

For inkjet processing, Newtonian low viscosity solutions are recommended. In our case, a PEDOT:PSTFSI $80 \mathrm{kDA}$ ink at concentrations under $0.55 \%$ wt. has no yield stress and may even be Newtonian at lower concentrations. The viscosity of our inks at $0.5 \%$ wt. is similar to that of the commercial PEDOT:PSS inks (Clevios PH 1000 and Orgacon IJ 1000).

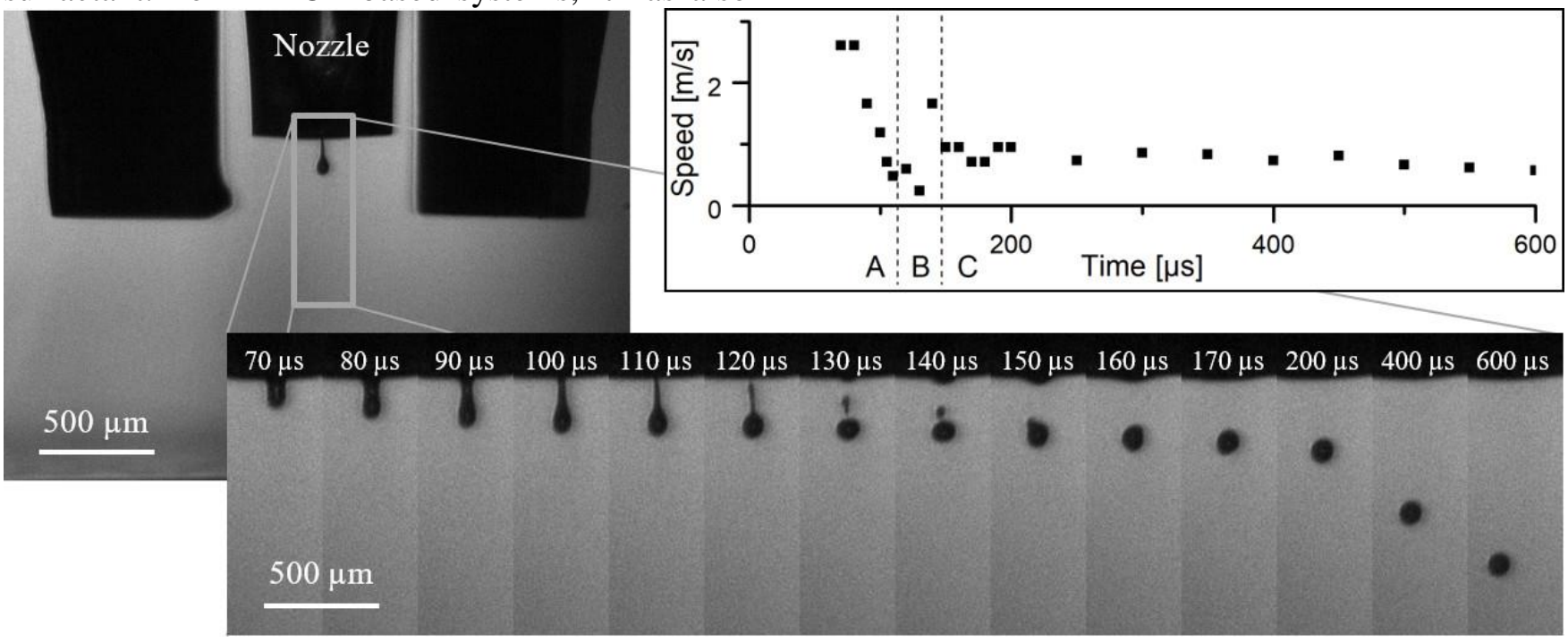

Figure 5. Photos of a drop of $0.5 \% \mathrm{wt}$ PEDOT:PSTFSI $80 \mathrm{kDa}$ ink ejected during inkjet printing from a $50 \mu \mathrm{m}$ nozzle and schematic of the speed of the drop divided in three zone : A) drop attached to the capillary, B) detachment of the drops (one principal and one satellite) and then merging of the satellite drop with the principal drop, C) free falling of the drop at a speed near $1 \mathrm{~m} / \mathrm{s}$.

We have used the $0.5 \%$ wt. solution to make films using an inkjet printer. Before use, the solution was sonicated for a few seconds and filtered with a $0.45 \mu \mathrm{m}$ PTFE filter. Very stable drops can be obtained from the printer nozzle. For higher concentrations however, $0.7 \%$ wt. for example, printing becomes very difficult, and the drops are highly unstable and create several satellite drops. 
Clearly, low concentrations and absence of yield stress play an important role. Considering that the drop ejection speed is of the order of $1-10 \mathrm{~m} / \mathrm{s}\left({ }^{16}\right.$ and [Figure 5]) and that the inkjet nozzle diameter is $50 \mu \mathrm{m}$, the shear rate at the nozzle can be very high and roughly $\dot{\gamma} \approx \frac{v}{d}=2 \cdot 10^{4}-2 \cdot 10^{5} s^{-1}$. The viscosity of the solution at $0.5 \%_{\mathrm{wt}}$ can be extrapolated to this shear rate by using the power law parameters, as $\eta=k \dot{\gamma}^{n-1}=2-7 \mathrm{mPa}$. $s$ which is close to the viscosity recommended for inkjet printers (5-40 mPa.s $)^{15,16}$.

For doctor blading, a viscous ink is recommended to reduce retraction or spreading effects near the contact line. The presence of a yield stress and an elastic modulus are beneficial since spreading or retraction can also be reduced or inhibited. We have used a concentration of $1 \%_{\mathrm{wt}}$ of PEDOT:PSTFSI ${ }_{80 \mathrm{kDA}}$ which has a yield stress $\tau_{0}$ of about $1 \mathrm{~Pa}$ and an elastic modulus $G^{\prime}$ of about $100 \mathrm{~Pa}$.
The films obtained using the inkjet printer as well as the Doctor blade are shown in Figure 6. The schematics give a brief overview of the techniques and the photographs show the obtained films. For both techniques, the films are relatively homogeneous and their mean thickness profile was obtained using a profilometer.

For screen-printing, the inks need to be highly shear thinning and to have sufficient elastic moduli. The ink should be able to flow through the mesh when the squeegee applies a high shear, but the ink layer should gel on the substrate to hold in place. For this last deposition process, we have used different solution concentrations between 0.9 and $1.4 \%$ wt. All these solutions have the right viscoelastic properties. However, and despite the fact that the rheology of the fluid is in the desired range, heterogeneous films were obtained [Figure 6]. We believe that the heterogeneity is due to wettability problems of the solutions with respect to the screens used as alluded to in section II.
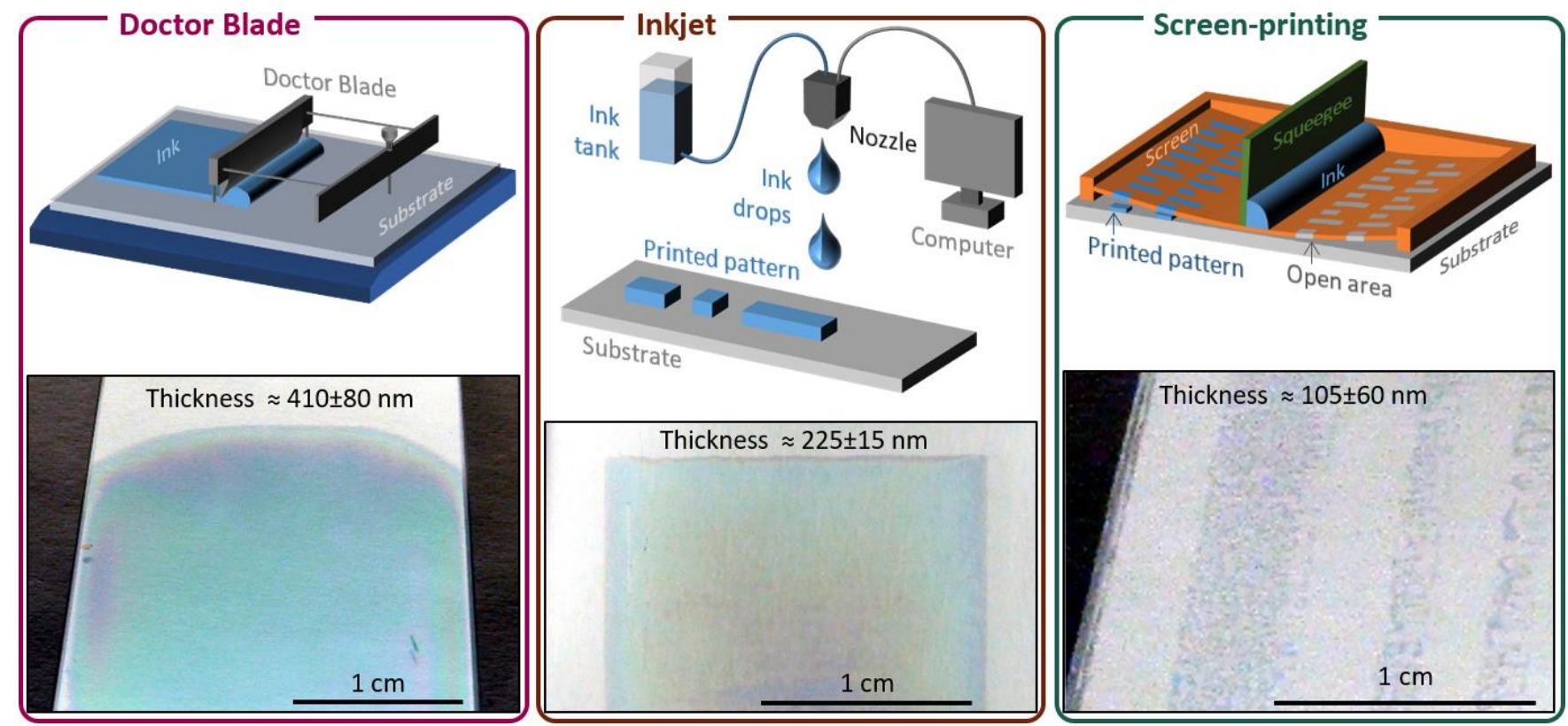

Figure 6. Schematics of the deposition processes and photos of films deposited by a) doctor blade, b) inkjet and c) screen-printing.

Last, an attempt at printing heterogeneous patterns in the form of parallel lines has been carried out. It has been shown that for aqueous shear thinning solutions, with a high extensional viscosity and capillary number $C a=\frac{\eta(\dot{\gamma}) \times v}{\Gamma}$ in the range of $10^{-3}$ $10^{-1}$, thin lines can be deposited by using a soft blade deposition technique on hydrophobic substrates. ${ }^{25}$ The extensional properties of $1 \% \mathrm{wt}$ PEDOT:PSTFSI $80 \mathrm{kDA}$ inks, which have a $\mathrm{Ca}$ in the desired range, are not sufficient and the deposition gives rise to aligned drops as can be seen in Figure 7.a. In order to increase the extensional properties of the solution, a high molar mass neutral polymer, PEO $8000 \mathrm{kDa}$, was added. High molar mass polymers such as PEO are known to increase the extensional properties of aqueous solutions ${ }^{26}$. The rheology of the solution, and therefore the value of the capillary number, was tuned by varying both the 
concentration of PEO and PEDOT:PSTFSI. The optimized formulation of $0.3 \% \mathrm{wt}$ PEDOT:PSTFSI $80 \mathrm{kDA}$ and $5000 \mathrm{ppm}$ PEO $8000 \mathrm{kDa}$ allows to form lines using deposition speeds between 0.1 and $2 \mathrm{~mm} / \mathrm{s}$. Figure 7.b shows both the formation of lines and drops connected by lines during the deposition process and Figure 7.c shows more developed lines observed after the drying of the ink. No surfactant was added for these experiments. Indeed, in this technique the dewetting of the ink onto the hydrophobic substrate is essential.

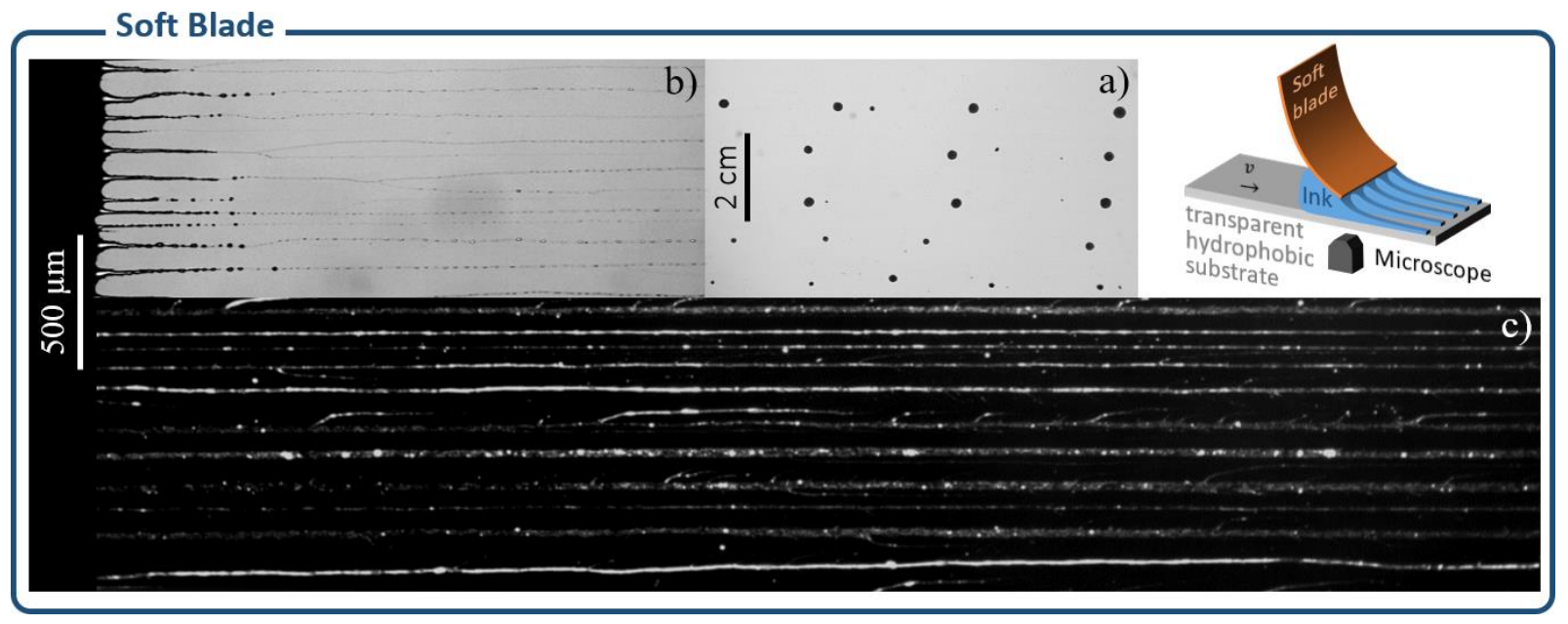

Figure 7. Schematic of the soft blade depositions process (the ink was deposited under the blade and the substrate, a silanized glass, was then moved at different speeds) and photo of the depositions: a) aligned dots (1\%wt PEDOT:PSTFSI $80 \mathrm{kDA})$; b) lines of $0.3 \% \mathrm{wt}$ PEDOT:PSTFSI $80 \mathrm{kDA}+5000 \mathrm{ppm}$ PEO $8000 \mathrm{kDa}$ during the deposition, and c) after drying (phase contrast image).

IV) Characterization of the deposited films: optoelectronic properties for transparent electrodes

In this section, we discuss the properties of the films obtained in the previous section in terms of their optoelectronic properties: the conductivity of the films and their transparency.

The electrical conductivity $\sigma$ of the films, which is the intrinsic property related to the mobility of the materials' electrical charges, was calculated using the thickness $t$ (obtained with a profilometer), and the sheet resistance $R_{S}$ (measured with a four-point probe) with the relation: $=\frac{1}{t \times R_{S}}$.

The transmittance $T$ of the films was measured with a UV-spectrometer at $550 \mathrm{~nm}: T=\frac{I}{I_{0}}$ where $I$ is the transmitted intensity and $I_{0}$ is the intensity of the incident light.

To compare transparent electrodes, the most commonly used feature is the so called Figure of Merit $(F o M)^{27,28}$. This FoM is the ratio of the electrical conductance $\sigma_{d c}$ on the optical conductance $\sigma_{o p t}$ defined as follows: $F o M=\frac{\sigma_{d c}}{\sigma_{o p t}}=$ $\frac{188,5}{\left(\frac{1}{\sqrt{T_{550 \mathrm{~nm}}}}-1\right) R_{S}}$ where $R_{S}$ is the sheet resistance, and
$T_{550 \mathrm{~nm}}$ is the transmittance at $550 \mathrm{~nm}$ of the printed films.

Our results are summarised in Table 1 which shows the rheological properties needed for each process, inkjet, doctor blade, screen-printing, the concentration ranges relevant for these processes, as well as the optoelectronic properties of the films obtained.

Note that sheet resistances in the range 55$128 \Omega / \square$ (doctor blade) and 100-180 $\Omega / \square$ (inkjet) were measured for films of thicknesses comprised between $190 \mathrm{~nm}$ and $580 \mathrm{~nm}$. The measured conductivities $(230-320 \mathrm{~S} / \mathrm{cm})$ for films obtained with doctor blade coating and (240-380 S/cm) for films obtained using inkjet printing are roughly the same. Such values are comparable, albeit smaller, to the conductivity of ITO (in the range of $\left.10^{3} \mathrm{~S} / \mathrm{cm}\right)^{2}$.

Depending on the thickness, different transmittances between 72 and $93 \%$ (72-86\% for doctor blade and $85-93 \%$ for inkjet printing) were measured, which is in the range of the transmittance of ITO films $\left(80-95 \%^{2}\right)$. 
Table 1. Formulation and rheology needed for three depositions processes and corresponding optoelectronic properties

\begin{tabular}{|c|c|c|c|c|c|c|c|c|}
\hline Process & Viscosity & $\begin{array}{l}\text { Shear } \\
\text { thinning }\end{array}$ & $\begin{array}{l}\text { Elasticity \& } \\
\text { Viscosity }\end{array}$ & $\begin{array}{c}{\left[P E D O T: P S T F S I_{80 k D a}\right]} \\
(\% \mathrm{wt})\end{array}$ & $\begin{array}{c}\mathrm{t} \\
(\mathrm{nm})\end{array}$ & $\begin{array}{c}\sigma \\
(\mathrm{S} / \mathrm{cm})\end{array}$ & $\begin{array}{c}T \\
(\%)\end{array}$ & FoM \\
\hline Inkjet & $\begin{array}{l}\text { Weak } \\
\text { 5-40 mPa.s }\end{array}$ & $\begin{array}{c}\text { Not } \\
\text { necessar } \\
\mathrm{y}\end{array}$ & $G^{\prime}<G^{\prime \prime}$ & $\approx 0.5$ & $268 \pm 102$ & $297 \pm 76$ & $90 \pm 4$ & $27 \pm 4$ \\
\hline $\begin{array}{l}\text { Doctor } \\
\text { Blade }\end{array}$ & $\begin{array}{l}\text { Intermediate } \\
(0.1-10 \mathrm{~Pa} . \mathrm{s} \\
\left.\text { for } 1-10^{3} \mathrm{~s}-1\right)\end{array}$ & $\begin{array}{c}\text { Not } \\
\text { necessar } \\
\mathrm{y}\end{array}$ & $G^{\prime}>G^{\prime \prime}$ & $\approx 0.9-1$ & $458 \pm 224$ & $276 \pm 33$ & $80 \pm 9$ & $19 \pm 2$ \\
\hline $\begin{array}{l}\text { Screen- } \\
\text { printing }\end{array}$ & $\begin{array}{c}\text { High } \\
(1-100 \text { Pa.s } \\
\left.\text { for } 1-10^{3} \mathrm{~s}-1\right)\end{array}$ & Yes & $G^{\prime}>G^{\prime \prime}$ & $0.9<\mathrm{C}<1.4$ & \multicolumn{4}{|c|}{ Inhomogeneous layer [Figure 6] } \\
\hline
\end{tabular}

Our measurements, Table 1, show that a FoM between 16 and 23 is obtained for films deposited by using doctor blade processing while for films obtained using inkjet printing, which are more transparent but have similar conductivities, a FoM between 23 and 31 is obtained. These results are near the minimum FoM needed for transparent electrodes in industry, evaluated at $35\left(\mathrm{R}_{\mathrm{s}}<100 \Omega / \square\right.$, and $\mathrm{T}>90 \%)^{1}$. Clearly, PEDOT:PSTFSI is a good candidate for making transparent and flexible electrodes.

\section{CONCLUSIONS}

This study has shown that PEDOT:PSTFSI inks can be easily formulated to be used in various deposition processes. No viscosity enhancers or other additives are needed to obtain viscous or gel like water-based inks. The processability of these inks is controlled by their viscosity and rheological properties, which can be tuned by simply varying the concentration of the solution or the molar mass of the polyanion. Formulation with neutral high molar mass polymers allows increasing the extensional properties of the inks and enables deposition through a soft blade technique for the formation of linear patterns. Finally, formulation with surfactant further improves the wettability of the ink, while the use of high boiling point solvents as conductivity enhancing agents allows increasing the conductivity of the dried ink layers without modifying the rheological properties of the ink. Interestingly, the optoelectronic features of PEDOT transparent conductive films were maintained whatever the deposition technique used. Both doctor blading and inkjet printing showed good promise, for further industrial and academic developments, reaching figures of merit up to 31 .

\section{MATERIALS AND METHODS}

I) Materials

The chemicals used during the synthesis are the following. Acetone, ethanol, isopropanol, oxalyl chloride, sodium 4-vinylbenzenesulfonate, dichloromethane, hydrochloric acid, potassium carbonate, 2,2'-azobis(2-methylpropionitrile) (AIBN), Ammonium persulfate and iron III chloride were purchased from Sigma Aldrich. N,Ndimethylformamide (DMF) and Dry-Acetonitrile are from Acros; triethylamine and sodium bicarbonate are from Fisher; trifluoromethanesulfonamide and S-dodecyl- $\mathrm{S}^{\prime}$ ( $\alpha, \alpha^{\prime}$-dimethyl- $\alpha^{\prime \prime}$-acetic acid) trithiocarbonate (CTA) from ABCR. Lewatit S100 KR and MP 62 WS were purchased from Lanxess.

All products were used without further purification.

To formulate the ink, Dimethyl sulfoxide (DMSO), Zonyl FS-300 fluorosurfactant and Polyethylene oxide (PEO) (Mw: 8000kDa) (from Sigma Aldrich) and Ethylene glycol (EG) (from Fisher) were used.

\section{II) Methods}

\section{Synthesis: from monomer to polyanion to complex PEDOT:PSTFSI}

The synthesis of the monomer potassium 4-styrene trifluoromethyl (bissulfonylimide) (STFSIK) was performed as described in the literature ${ }^{29}$. A yield around $40 \%$ was obtained. The synthesis of the polyanion potassium salt of poly(4-styrene trifluoromethyl (bissulfonylimide)) (PSTFSIK) followed previous studies ${ }^{30}$ with a yield around $50 \%$. The chemical structure of the STFSIK and PSTFSIK were checked using ${ }^{1} \mathrm{H}-\mathrm{NMR}$ spectroscopy. They 
were recorded on a Bruker Avance III HD 400 equipped with a $5 \mathrm{~mm}$ Bruker multinuclear direct probe. The measurements were done in deuterated DMSO at $298 \mathrm{~K}$ and $100.7 \mathrm{MHz}$. The molar mass of the PSTFSIK was tracked by size-exclusion chromatography (SEC) in DMF with $\mathrm{LiBr}$, using toluene as flow marker. The measurements were done at $75^{\circ} \mathrm{C}$ on an Agilent PL-GPC 220 High Temperature Chromatograph calibrated with polystyrene standards. Two molar masses were obtained: i.e. 80 and $250 \mathrm{kDa}$.

The synthesis of the complex poly(3,4ethylenedioxythiophene):poly(4-styrene

trifluoromethyl (bissulfonylimide))

(PEDOT:PSTFSI) was done as described in the literature $^{31}$. The solution was then concentrated using an ultrafiltration cell. The concentration of the solution was checked by using a UV-360 Shimadzu UV-VIS-NIS-Spectrophotometer. The absorbance was measured in a $1 \mathrm{~mm}$ optical glass cell and then related to the concentration by using the BeerLambert law determined previously as $C=0.565 \times$ Abs. A hydrodynamic radius of $120-150 \mathrm{~nm}$ was measured using Dynamic Light Scattering (DLS) on diluted solutions of the complex PEDOT:PSTFSI 80k Da. Liquid Atomic Force Microscopy (AFM) was performed on a Bruker Dimension FastScan AFM to characterize the topology of polymers in very diluted solutions deposited on HOPG (Highly Ordered Pyrolytic Graphite) [See Figure S.7 in Supplementary Information]: the thickness of the complex PEDOT:PSTFSI $80 \mathrm{kDA}$ is in the range of few nanometers (1.5-4 $\mathrm{nm})$, and its width is in the range of $15-30 \mathrm{~nm}$. During the measurement, the polymer lies flat on the substrate which explains the difference of one order of magnitude between the thickness and the width.

\section{Substrate preparation}

Before printing, microscope slides were cleaned by sonication for 15 minutes in ethanol, acetone and isopropanol. For the soft blade deposition, glass slides were silanized using Octadecyltrichlorosilane $(\mathrm{OTS})^{25}$ in toluene ${ }^{32}$ and then washed with chloroform. The purpose of this reaction is to functionalize a hydrophilic surface containing hydroxyl groups and render it hydrophobic. A Krüss Drop Shape Analyzer DSA100 was used with a contact angle method to measure the surface free energy of the silanized glasses at $20 \mathrm{mN} / \mathrm{m}$ with almost only a dispersive contribution. A contact angle between water drops and silanized glass of $107^{\circ}$ was obtained.

\section{Formulations of PEDOT:PSTFSI solutions}

The PEDOT:PSTFSI inks at different concentrations (from pure water to $1.42 \% \mathrm{wt}$ ) were then formulated with $5 \%$ vol of a high boiling point solvent (DMSO or EG) to increase the final conductivity $^{24,33}$ after deposition, and sometimes $0.04 \%$ wt anionic fluorosurfactant (Zonyl FS-300) was added to decrease the surface tension of the ink from 72 to $24 \mathrm{mN} / \mathrm{m}$ and allow deposition onto plastic substrates by doctor blade and inkjet, or to allow the ink to flow through the mesh of the screen in screen-printing. The concentration $0.04 \%_{\mathrm{wt}}$ of surfactant was chosen as it is above and near the critical micelle concentration of the surfactant in water [See Figure S.3 in Supplementary Information]. The rheological properties of PEDOT:PSTFSI inks formulated with and without surfactant and/or high boiling point solvent were measured and found quite similar to the properties of the solutions with no additives [See Figure S.5 in Supplementary Information].

For the soft blade deposition, a high molar mass neutral polymer $\left(\mathrm{PEO}_{8000 \mathrm{kDa}}\right)$ was used to increase the elasticity of the ink.

\section{Processing of PEDOT:PSTFSI inks}

Four depositions processes were used: doctor blade to deposit flat tint, screen-printing and inkjet to print patterns (with and without contact) [Figure 6].

An Erichsen Doctor Blade was used to deposit inks on microscope slides. Different air gaps were used between 50 and $150 \mu \mathrm{m}$ with a speed of 5 or $10 \mathrm{~mm} / \mathrm{s}$.

A single nozzle Microfab Jetlab4 inkjet printer was used with a MJ-ATP-01-050 nozzle. Different parameters were adjusted to stabilize drops. Printing was done on glass.

For screen-printing, a mask was first created on a screen (mesh size of 150 wires/cm with a diameter of the wires of $30 \mu \mathrm{m}$ ): the designed pattern was printed with a Studio 3005AC Toshiba copier two times on PET to create a mask. Then a CDF Vision $15 \mu \mathrm{m}$ or $30 \mu \mathrm{m}$ emulsion (a diazo dual-cure capillary film) was placed on the screen with deionized-water. After drying, the mask was exposed 7 to 10 minutes to UV-light and then revealed using a Kärcher pressure washing. An EKRA X5 screen-printer was then used with 
squeegee in modified polyurethane and the dried screen. The ink was deposited with a pressure of $120 \mathrm{~N}$, an air gap between the screen and the substrate of $1 \mathrm{~mm}$, and a squeegee speed of $180 \mathrm{~mm} / \mathrm{s}$.

Inkjet and screen-printing were done at the platform ELORPrintTec (clean room environment).

Soft blade processing has been shown to allow the deposition of lines of a water-based polymeric ink on a hydrophobic substrate by using the instability of the contact line near the blade ${ }^{25}$ : lines should be obtained for capillary numbers $C a$ in a certain range $\left(10^{-2}-10^{-1}\right)$ and with highly shear-thinning polymer solutions. Depositions were done with a sheet of Mylar $1.5 \mathrm{x} 4 \mathrm{~cm}^{2}$ with a thickness of $200 \mu \mathrm{m}$ as soft blade. In this deposition technique, the blade was fixed and the speed of the substrate was set between $0.02 \mathrm{~mm} / \mathrm{s}$ and $20 \mathrm{~mm} / \mathrm{s}$ on silanized glass. Images of the obtained films and patterns were recorded with a Hamamatsu Orca flash 2.8 fast camera.

\section{Drying of the films}

After each of the three first deposition processes, PEDOT:PSTFSI patterns were dried 5 minutes at a temperature of $120^{\circ} \mathrm{C}$. For the soft blade, the lines dried before the end of the deposition at ambient temperature.

\section{III) Characterizations}

\section{Characterization of the formulated inks}

An Anton Paar MCR302 rheometer was used with a CP50-1 ${ }^{\circ}$ geometry (cone $50 \mathrm{~mm}-1^{\circ} /$ plate). Different shear rates and shear stresses were applied to measure the shear viscosity and the viscoelastic behavior of the solutions.

A Krüss Drop Shape Analyzer DSA100 was used to measure surface tensions of the fluid solutions using a pendant drop method and a Young-Laplace model: $\Delta P=\left(P_{\text {int }}-P_{\text {ext }}\right)=\Gamma\left(\frac{1}{R_{1}}+\frac{1}{R_{2}}\right)$ where $\Delta P$ is the pressure difference at the interface between the drop and the surrounding air, $R_{1}$ and $R_{2}$ are the principal radii of the drop, and $\Gamma$ is the surface tension of the fluid ${ }^{34,35}$. For concentrated solutions, the surface tension was measured using Tate's law: $m_{\text {drop }} \times g=2 \pi \times r_{\text {capillary }} \times \Gamma$ where $m_{\text {drop }}$ is the weight of one drop, $g$ is the gravitational force, $r_{\text {capillary }}$ is the internal radius of the needle, and $\Gamma$ is the surface tension of the fluid ${ }^{36,37}$.

\section{Characterization of the depositions}

A Bruker Dektak XT-A profilometer was used to measure the thickness of the films.
A Jandel RM3-AR four point probes was used to measure the sheet resistance of the films.

\section{AUTHOR INFORMATION}

\author{
Corresponding Author \\ * hamid.kellay@u-bordeaux.fr, eric.cloutet@u-bordeaux.fr and \\ georges.hadziioannou@u-bordeaux.fr
}

\section{Author Contributions}

The manuscript was written through contributions of all authors. All authors have given approval to the final version of the manuscript. A.Glasser carried out the experiments. The data were analyzed by all authors.

\section{ACKNOWLEDGMENT}

We would like to acknowledge the LabEx AMADEUS ANR-10LABEX-0042-AMADEUS, the program of Excellence Initiative IdEx ANR-10-IDEX-003-02, the Region Nouvelle Aquitaine, and the LCPO-Arkema INDUSTRIAL CHAIR "HOMERIC" ANR-13CHIN-0002-01 for financial support. This work was performed within the framework of the Equipex ELORPrintTec ANR-10EQPX-28-01. A.Glasser acknowledges M.Mumtaz and M.Bousquet for their help during the synthesis of the STFSI and PSTFSI, and PEDOT:PSTFSI respectively.

\section{ABBREVIATIONS}

PEDOT, poly(3,4-ethylene dioxythiophene); PSS, poly(styrenesulfonate); PSTFSI, poly(4-styrene trifluoromethyl(bissulfonylimide)); PL, power-law; HB, Herschel-Bulkley; STFSIK, potassium 4styrene trifluoromethyl (bissulfonylimide); AIBN, 2,2'-azobis(2-methylpropionitrile); DMF, N,Ndimethylformamide; CTA, S-dodecyl-S'-( $\alpha, \alpha^{\prime}-$ dimethyl- $\alpha^{\prime \prime}$-acetic acid) trithiocarbonate; DMSO, Dimethyl sulfoxide; EG, Ethylene Glycol; PEO, Polyethylene Oxide; OTS, Octadecyltrichlorosilane; RMN, Nuclear magnetic resonance; SEC, sizeexclusion chromatography; DLS, Dynamic Light Scattering; AFM, Atomic Force Microscopy; HOPG, Highly Ordered Pyrolytic Graphite; SEM, Scanning Electron Microscope; PET, Polyethylene terephthalate; PTFE, Polytetrafluoroethylene; FoM, Figure of Merit.

\section{REFERENCES}

(1) De, S.; Lyons, P. E.; Sorel, S.; Doherty, E. M.; King, P. J.; Blau, W. J.; Nirmalraj, P. N.; Boland, J. J.; Scardaci, V.; Joimel, J.; et al. Transparent, Flexible, and Highly Conductive Thin Films Based on Polymer-Nanotube Composites. ACS Nano 2009, 3 (3), 714-720. https://doi.org/10.1021/nn800858w.

(2) Cao, W.; Li, J.; Chen, H.; Xue, J. Transparent Electrodes for Organic Optoelectronic Devices: A Review. JPE 2014, 4 (1), 040990. https://doi.org/10.1117/1.JPE.4.040990.

(3) Park, Y.; Choong, V.; Gao, Y.; Hsieh, B. R.; Tang, C. W. Work Function of Indium Tin Oxide Transparent Conductor Measured by Photoelectron Spectroscopy. Appl. Phys. Lett. 1996, 68 (19), 2699 2701. https://doi.org/10.1063/1.116313.

(4) A Review of Flexible OLEDs Toward Highly Durable Unusual Displays - IEEE Journals \& Magazine 
https://ieeexplore.ieee.org/abstract/document/7827119 (accessed Feb $28,2019)$.

(5) Raupp, S.; Daume, D.; Tekoglu, S.; Merklein, L.; Lemmer, U.; Hernandez-Sosa, G.; Sauer, H. M.; Dörsam, E.; Scharfer, P.; Schabel, W. Slot Die Coated and Flexo Printed Highly Efficient SMOLEDs. Advanced Materials Technologies 2017, 2 (2), 1600230. https://doi.org/10.1002/admt.201600230.

(6) Pali, L. S.; Jindal, R.; Garg, A. Screen Printed PEDOT:PSS Films as Transparent Electrode and Its Application in Organic Solar Cells on Opaque Substrates. J Mater Sci: Mater Electron 2018, 29 (13), 11030-11038. https://doi.org/10.1007/s10854-018-9185-y.

(7) Sico, G.; Montanino, M.; De Girolamo Del Mauro, A.; Imparato, A.; Nobile, G.; Minarini, C. Effects of the Ink Concentration on Multi-Layer Gravure-Printed PEDOT:PSS. Organic Electronics 2016, 28, 257-262. https://doi.org/10.1016/j.orgel.2015.10.031.

(8) Hrehorova, E. Materials and Processes for Printed Electronics: Evaluation of Gravure Printing in Electronics Manufacture. Dissertations 2007.

(9) Kommeren, S.; Coenen, M. J. J.; Eggenhuisen, T. M.; Slaats, ThijsM. W. L.; Gorter, H.; Groen, P. Combining Solvents and Surfactants for Inkjet Printing PEDOT:PSS on P3HT/PCBM in Organic Solar Cells. Organic Electronics 2018, 61, 282-288. https://doi.org/10.1016/j.orgel.2018.06.004.

(10) Hoath, S. D.; Hsiao, W.-K.; Martin, G. D.; Jung, S.; Butler, S. A.; Morrison, N. F.; Harlen, O. G.; Yang, L. S.; Bain, C. D.; Hutchings, I. M. Oscillations of Aqueous PEDOT:PSS Fluid Droplets and the Properties of Complex Fluids in Drop-on-Demand Inkjet Printing. Journal of Non-Newtonian Fluid Mechanics 2015, 223, 28 36. https://doi.org/10.1016/j.jnnfm.2015.05.006.

(11) Yang, J.; Lin, Y.; Zheng, W.; Liu, A.; Cai, W.; Yu, X.; Zhang, F.; Liang, Q.; Wu, H.; Qin, D.; et al. Roll-to-Roll Slot-DiePrinted Polymer Solar Cells by Self-Assembly. ACS Appl. Mater. $\begin{array}{lllll}\text { Interfaces } & \mathbf{2 0 1 8}, & 10 & \text { (26), 22485-22494. }\end{array}$ https://doi.org/10.1021/acsami.8b05673.

(12) Ji, G.; Wang, Y.; Luo, Q.; Han, K.; Xie, M.; Zhang, L.; Wu, N.; Lin, J.; Xiao, S.; Li, Y.-Q.; et al. Fully Coated Semitransparent Organic Solar Cells with a Doctor-Blade-Coated Composite Anode Buffer Layer of Phosphomolybdic Acid and PEDOT:PSS and a SprayCoated Silver Nanowire Top Electrode. ACS Appl. Mater. Interfaces 2018, 10 (1), 943-954. https://doi.org/10.1021/acsami.7b13346.

(13) Nadgorny, M.; Ameli, A. Functional Polymers and Nanocomposites for 3D Printing of Smart Structures and Devices. ACS Appl. Mater. Interfaces 2018, 10 (21), 17489-17507. https://doi.org/10.1021/acsami.8b01786.

(14) Izdebska, J.; Thomas, S. Printing on Polymers: Fundamentals and Applications; William Andrew, 2015.

(15) Hoath, S. D. Fundamentals of Inkjet Printing: The Science of Inkjet and Droplets; John Wiley \& Sons / Wiley-VCH Verlag GmbH \& CoKGaA: Weinheim, Germany, 2016.

(16) Zapka, W. Handbook of Industrial Inkjet Printing: A Full System Approach; John Wiley \& Sons, 2018.

(17) Abbott, S. How to Be a Great Screen Printer, Macdermid Autotype Limited.; HowTo eBook; 2008.

(18) Bingham, E. C. An Investigation of the Laws of Plastic Flow. Bulletin of the Bureau of Standards 1916, 13 (2), 309. https://doi.org/10.6028/bulletin.304.

(19) Ostwald, W. Ueber die Geschwindigkeitsfunktion der Viskosität disperser Systeme. I. Kolloid-Zeitschrift 1925, 36 (2), 99117. https://doi.org/10.1007/BF01431449.

(20) Herschel, W. H.; Bulkley, R. Konsistenzmessungen von Gummi-Benzollösungen. Kolloid-Zeitschrift 1926, 39 (4), 291-300. https://doi.org/10.1007/BF01432034.

(21) Mezger, T. G. The Rheology Handbook: For Users of Rotational and Oscillatory Rheometers; Vincentz Network GmbH \& Co KG, 2006.

(22) Hofmann, A. I.; Smaal, W. T. T.; Mumtaz, M.; Katsigiannopoulos, D.; Brochon, C.; Schütze, F.; Hild, O. R.; Cloutet, E.; Hadziioannou, G. An Alternative Anionic Polyelectrolyte for Aqueous PEDOT Dispersions: Toward Printable Transparent Electrodes. Angewandte Chemie International Edition 2015, 54 (29), 8506-8510. https://doi.org/10.1002/anie.201503024.
(23) Hofmann, A. Aqueous Dispersions of Conducting Polymers for Opto-Electronic Applications. Thèse de doctorat, Université de Bordeaux: Bordeaux, 2016.

(24) Shi, H.; Liu, C.; Jiang, Q.; Xu, J. Effective Approaches to Improve the Electrical Conductivity of PEDOT:PSS: A Review. $A d v$. Electron. Mater. $\quad \mathbf{2 0 1 5}, 1$ (4), n/a-n/a. https://doi.org/10.1002/aelm.201500017.

(25) Deblais, A.; Harich, R.; Colin, A.; Kellay, H. Taming Contact Line Instability for Pattern Formation. Nature $\begin{array}{llll}\text { Communications } & \mathbf{2 0 1 6}, & 7, & 12458 .\end{array}$ https://doi.org/10.1038/ncomms12458.

(26) Ingremeau, F.; Kellay, H. Stretching Polymers in DropletPinch-Off Experiments. Phys. Rev. X 2013, 3 (4), 041002. https://doi.org/10.1103/PhysRevX.3.041002.

(27) Li, D.; Han, T.; Ruan, H. Solution-Assembled Ordered Grids Constructed with Silver Nanowires as Transparent Conductive Electrodes. ACS Omega 2018, 3 (7), 7191-7195. https://doi.org/10.1021/acsomega.8b01320.

(28) van de Groep, J.; Spinelli, P.; Polman, A. Transparent Conducting Silver Nanowire Networks. Nano Lett. 2012, 12 (6), 31383144. https://doi.org/10.1021/nl301045a.

(29) Meziane, R.; Bonnet, J.-P.; Courty, M.; Djellab, K.; Armand, M. Single-Ion Polymer Electrolytes Based on a Delocalized Polyanion for Lithium Batteries. Electrochimica Acta 2011, 57, 14-19. https://doi.org/10.1016/j.electacta.2011.03.074.

(30) Mumtaz, M.; Aissou, K.; Katsigiannopoulos, D.; Brochon, C.; Cloutet, E.; Hadziioannou, G. A Well-Defined Polyelectrolyte and Its Copolymers by Reversible Addition Fragmentation Chain Transfer (RAFT) Polymerization: Synthesis and Applications. RSC Adv. 2015, 5 (119), 98559-98565. https://doi.org/10.1039/C5RA19730A.

(31) Hofmann, A. I.; Katsigiannopoulos, D.; Mumtaz, M.; Petsagkourakis, I.; Pecastaings, G.; Fleury, G.; Schatz, C.; Pavlopoulou, E.; Brochon, C.; Hadziioannou, G.; et al. How To Choose Polyelectrolytes for Aqueous Dispersions of Conducting PEDOT Complexes. Macromolecules 2017, 50 (5), 1959-1969. https://doi.org/10.1021/acs.macromol.6b02504.

(32) McGovern, M. E.; Kallury, K. M. R.; Thompson, M. Role of Solvent on the Silanization of Glass with Octadecyltrichlorosilane. Langmuir $1994, \quad 10 \quad$ (10), 3607-3614 https://doi.org/10.1021/la00022a038.

(33) Palumbiny, C. M.; Heller, C.; Schaffer, C. J.; Körstgens, V.; Santoro, G.; Roth, S. V.; Müller-Buschbaum, P. Molecular Reorientation and Structural Changes in Cosolvent-Treated Highly Conductive PEDOT:PSS Electrodes for Flexible Indium Tin OxideFree Organic Electronics. J. Phys. Chem. C 2014, 118 (25), 13598 13606. https://doi.org/10.1021/jp501540y.

(34) Worthington, A. M. II. On Pendent Drops. Proc. R. Soc. Lond. $\quad 1881, \quad 32 \quad$ (212-215), 362-377. https://doi.org/10.1098/rspl.1881.0032.

(35) Berry, J. D.; Neeson, M. J.; Dagastine, R. R.; Chan, D. Y. C.; Tabor, R. F. Measurement of Surface and Interfacial Tension Using Pendant Drop Tensiometry. Journal of Colloid and Interface Science 2015, 454, 226-237. https://doi.org/10.1016/j.jcis.2015.05.012.

(36) Tate, T. XXX. On the Magnitude of a Drop of Liquid Formed under Different Circumstances. The London, Edinburgh, and Dublin Philosophical Magazine and Journal of Science 1864, 27 (181), 176-180. https://doi.org/10.1080/14786446408643645.

(37) Garandet, J. P.; Vinet, B.; Gros, P. Considerations on the Pendant Drop Method: A New Look at Tate's Law and Harkins' Correction Factor. Journal of Colloid and Interface Science 1994, 165 (2), 351-354. https://doi.org/10.1006/jcis.1994.1240. 
TOC

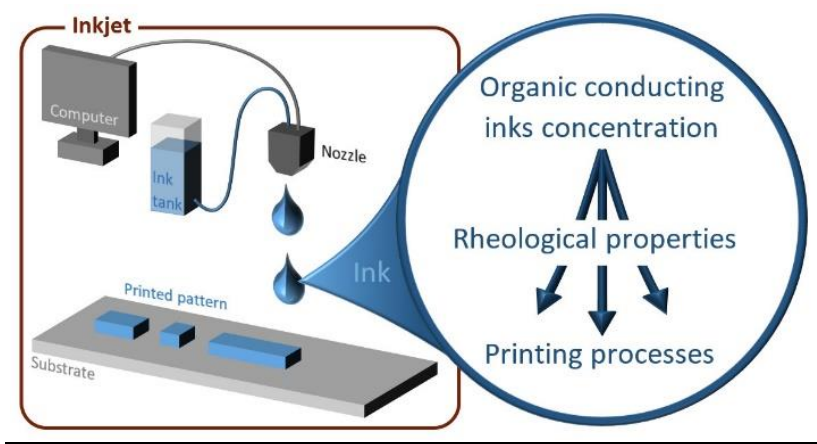

